\title{
Allopurinol attenuates caerulein induced acute pancreatitis in the rat
}

\author{
J R WISNER AND I G RENNER \\ From the Department of Medicine, Section of Gastroenterology, University of Southern California School of \\ Medicine, Los Angeles, California, USA
}

SUMMARY Oxygen derived free radicals have been implicated in the pathogenesis of acute pancreatitis in numerous animal models of the disease. The xanthine oxidase inhibitor allopurinol has been shown to attenuate pancreatic damage in canine and mouse models of acute pancreatitis presumably by preventing the generation of cytotoxic superoxide anions. We therefore examined whether allopurinol could attenuate pancreatic injury in conscious rats with caerulein induced acute pancreatitis. A continuous intravenous infusion of allopurinol $(20 \mathrm{mg} / \mathrm{kg} / \mathrm{h})$ for six hours along with an acute pancreatitis producing dose of caerulein $(10 \mu \mathrm{g} / \mathrm{kg} / \mathrm{h})$ reduced pancreas weights by approximately $45 \%$ and serum amylase concentrations by approximately $60 \%$ compared with rats intravenously infused with either caerulein alone or caerulein plus a lower dose $(10 \mathrm{mg} / \mathrm{kg} / \mathrm{h})$ of allopurinol. We conclude that the generation of oxygen derived free radicals via pancreatic xanthine oxidase represents an early and perhaps pivotal mechanism in the pathogenesis of acute pancreatitis.

Oxygen derived free radicals - for example, superoxide anion and hydroxyl radical, have been implicated recently in the pathogenesis of acute pancreatitis (AP).' Work by Sanfey et al $^{1-3}$ has shown in the isolated, perfused canine pancreas that acute pancreatitis induced by three different methods (a period of total arterial occlusion followed by reperfusion, partial pancreatic duct obstruction coupled with secretin administration, or perfusion of the pancreas with a free fatty acid) is significantly prevented by prior treatment with the free radical scavenging enzymes superoxide dismutase and catalase. Moreover, these workers also showed in the same models of acute pancreatitis that the xanthine oxidase inhibitor allopurinol also significantly lowered hyperamylasaemia in the pancreas perfusate and reduced pancreatic oedema. ${ }^{+}$Recent studies by Rutledge and coworkers in mice with diet induced acute pancreatitis showed that pretreatment with allopurinol or dimethylsulphoxide (DMSO) significantly reduced pancreatic oedema but failed to alter hyperamylasaemia or mortality rates.

Xanthine oxidase (derived from proteolytic conversion of the ubiquitous $\mathrm{NAD}^{+}$dependent enzyme

Address for correspondence: Dr J R Wisner. Jr. USC School of Medicine, HMR 902, 2025 Zonal Avenue, Los Angeles, CA 9(0)33, USA.

Received for publication 21 January 1988. xanthine dehydrogenase) uses molecular oxygen as a cofactor and converts tissue xanthine and hypoxathine to uric acid with superoxide anion and hydrogen peroxide as by products. The attenuation of acute pancreatitis in the canine and mouse models by allopurinol inhibition of xanthine oxidase is, therefore, consistent with the concept that allopurinol prevents the generation of cytotoxic superoxide anion. ${ }^{1-5}$

In the present study we have examined the effects of a continuous intravenous (iv) infusion of allopurinol on the development of caerulein induced acute pancreatitis in conscious rats. This model of acute pancreatitis is based on supramaximal stimulation of the pancreas with a CCK like secretagogue and characteristically results in an extensive pancreatic oedema, acinar cell vacuolisation and raised serum pancreatic enzyme concentrations as early as one hour after administration of the compound. . $^{\infty 13}$

\section{Methods}

RATS

Adult male Wistar rats (200-250 g bw) were purchased from Simonsen Laboratories, Gilroy, CA, USA and were deprived of food but not water for 18 hours before the experiment. 
Animals were anaesthetised by a single intraperitoneal (ip) injection of sodium pentobarbital (30) $\mathrm{mg} / \mathrm{kg}$ ) and the left external jugular vein was cannulated with PE-50 polyethylene tubing as previously described. ${ }^{13}$ The jugular cannula was exteriorised at the nape of the neck through a subcutaneous tunnel and after regaining consciousness rats were transferred to individual cages containing plastic blocks to restrict lateral movement. Immediately before the experiments a basal (0 time) tail vein blood sample $(0 \cdot 2 \mathrm{ml})$ was obtained. Continuous iv infusions of test substances were conducted using an Harvard Syringe Infusion Pump (Model 2681) at a flow rate of 0.5 $\mathrm{ml} / \mathrm{h}{ }^{.1213}$ Synthetic caerulein and allopurinol (Lot No. 43F-0165) were purchased from Sigma Chemical Co, St Louis, MO, USA. A working $7 \cdot 5 \%$ stock solution of allopurinol was mixed fresh each day in $1.0 \mathrm{~N} \mathrm{NaOH}$ and the desired final concentrations of iv infusions were subsequently prepared in normal saline. Caerulein was mixed fresh daily in the allopurinol excipient.

Rats were divided into three groups and received a continuous iv infusion of test substances for six hours according to the following regimens: group $I(n=6)=$ caerulein $(10 \mu \mathrm{g} / \mathrm{kg} / \mathrm{h})$ for induction of acute pancreatitis; group II $(\mathrm{n}=7)=$ caerulein $(10 \mu \mathrm{g} / \mathrm{kg} / \mathrm{h})+$ allopurinol $(10 \mathrm{mg} / \mathrm{kg} / \mathrm{h}) ;$ group III $(\mathrm{n}=5)=$ caerulein $(10 \mu \mathrm{g} / \mathrm{kg} / \mathrm{h})+$ allopurinol $(20 \mathrm{mg} / \mathrm{kg} / \mathrm{h})$.

After the six hour iv infusion period rats were anaesthetised with an ip injection of sodium pentobarbital $(30 \mathrm{mg} / \mathrm{kg})$. After laparotomy and recording of macroscopic observations on the pancreas, animals were killed by abdominal aorta exsanguination $(\mathrm{t}=6 \mathrm{~h}$ blood sample) and the pancreas was excised, trimmed of adhering fat and connective tissue and weighed to the nearest $(0 \cdot 1 \mathrm{mg}$. A portion of the pancreas was removed for histological examination.

Serum amylase concentrations were assayed by the
Phadebas test (Pharmacia Laboratories, Piscataway, $\mathrm{NJ}$, USA) routine in our laboratory ${ }^{* 13}$ and pancreas tissue was processed for light microscopy as previously described." The degree of macroscopic severity of acute pancreatitis was graded on a 0 to 5 scale and the criteria selected for evaluation are described in the legend of the Table. The macroscopic grading of the pancreas was analysed by an observer who was unaware of the animal's treatment group.

STATISTICAL ANALYSIS

Statistical evaluation of serum amylase data were accomplished using Student's two-tailed $t$ test for independent means ${ }^{14}$ and a $p$ value of $<0.05$ was considered to be statistically significant. The macroscopic data were analysed for statistical significance using the Wilcoxon's rank-sum test ${ }^{1+}$ with a $p$ value of $<0.01$ being considered to be statistically significant.

\section{Results}

MACROSCOPIC OBSERVATIONS

In confirmation of our previous findings ${ }^{\times 12}$ : the macroscopic appearance of the pancreas of rats killed after a six hour continuous iv infusion of caerulein (10 $\mu \mathrm{g} / \mathrm{kg} / \mathrm{h}$ ) was characterised by gross oedema and inflammation and peritoneal ascites was present (Table). No change in these parameters was evident in rats infused for six hours with the low dose of allopurinol $(10 \mathrm{mg} / \mathrm{kg} / \mathrm{h})+$ caerulein. By contrast, the macroscopic appearance of the pancreas in rats infused with the high dose of allopurinol $(20 \mathrm{mg} / \mathrm{kg} / \mathrm{h})$ +caerulein was characterised by minor to moderate oedema and inflammation and minimal ascitic fluid was present. These latter changes were significantly different from the macroscopic observations in rats infused with either caerulein alone or low dose allopurinol+caerulein (Table).

Table Serumamylase concentrations, pancreas weights, and macroscopic observations on the pancreas in rats intravenously infused for six house with caerulein $(C R)$ or $(R$ plus varying concentrations of allopurinol $(A L L O)$

\begin{tabular}{|c|c|c|c|c|c|}
\hline \multirow[b]{2}{*}{ Treatment } & \multirow[b]{2}{*}{$n$} & \multicolumn{2}{|c|}{ Serum amvlase' $(I U / \mathrm{ml})$} & \multirow{2}{*}{$\begin{array}{l}\text {-Pancrease weights } \\
\text { (g/loog body wt) }\end{array}$} & \multirow{2}{*}{$\begin{array}{l}\text { Macroscopic } \\
\text { observations }\end{array}$} \\
\hline & & Basal & $6 h$ & & \\
\hline CR $(10 \mu \mathrm{g} / \mathrm{kg} / \mathrm{h})$ & 6 & $10 \cdot(0)(1 \cdot 25)$ & $103(9 \cdot 3)^{*}$ & $0.973(0.093)$ & $4 \cdot 83(0 \cdot 17)$ \\
\hline CR $(10 \mu \mathrm{g} / \mathrm{kg} / \mathrm{h})+\operatorname{ALLO}(10 \mathrm{mg} / \mathrm{kg} / \mathrm{h})$ & 7 & $9.71(0.59)$ & $110(6 \cdot 1)^{*}$ & $0.958(0 \cdot 092)$ & $4 \cdot 86(0 \cdot 14)$ \\
\hline$C R(10 \mu \mathrm{g} / \mathrm{kg} / \mathrm{h})+\operatorname{ALLO}(20 \mathrm{mg} / \mathrm{kg} / \mathrm{h})$ & 5 & $7.26(1.53)$ & $41 \cdot 5(15 \cdot 2)^{*}+$ & $0.544(0 \cdot(049) \dagger$ & $3 \cdot 00(0 \cdot 27) \ddagger$ \\
\hline
\end{tabular}

All values represent the mean (SE). Values for macroscopic observations on the pancreas were derived from a 0-5 scoring system where $1=$ minor hyperaemia, no pancreatic ocdema or peritoneal ascites; $2-3=$ intensely hyperaemic, minor to moderate oedema with accentuation of pancreatic lobulation and minimal peritoneal ascites; 4-5=marked hyperaemia, gross oedema, and peritoneal ascites.

'Typical serum amylase concentrations and pancreas weights in normal, untreated control rats of comparable age and body weights to rats used in the present study are $8 \cdot(1) \pm 1.08 \mathrm{IU} / \mathrm{ml}(\mathrm{n}=5)$ and $0.490 \pm 0 .(022 \mathrm{~g} / 100 \mathrm{~g}$ body weight $(\mathrm{n}=5)$, respectively (unpublished observations). ${ }^{*} \mathrm{p}<0 .(0) 1$ compared with the appropriate basal value; ${ }^{\dagger} \mathrm{p}<0.01$ compared with rats given either $\mathrm{CR}$ alone or $\mathrm{CR}+$ low dose $\mathrm{Allo} ; \neq \mathrm{p}<0 .(0) 1$ compared with rats given either CR alone or CR+low dose Allo. 
PANCREAS WEIGHTS AND SERUM AMYLASE CONCENTRATIONS

The pancreas weights in rats infused with low dose allopurinol+caerulein were not significantly different from weights in rats infused with caerulein alone. Pancreas weights in rats given the high dose of allopurinol+caerulein however were significantly reduced by approximately $45 \%$ compared with rats infused with either caerulein alone or with low dose allopurinol+caerulein (Table).

Serum amylase concentrations were significantly raised by approximately nine to 10 -fold over basal $(0$ time) levels at the end of the six hour experiment in rats infused with caerulein alone (Table). No significant difference was observed in the six hour serum amylase concentrations between rats given caerulein alone and those infused with low dose allopurinol+ caerulein. By contrast, the six hour serum amylase concentration in rats given high dose allopurinol+ caerulein were significantly reduced by approximately $60 \%$ compared with rats treated with either caerulein alone or with low dose allopurinol+ caerulein (Table).

\section{MICROSCOPIC OBSERVATIONS}

The most prominent histological features of the pancreas in rats iv infused with caerulein alone or with low dose allopurinol+caerulein were the presence of marked interstitial oedema and large numbers of variable sized vacuoles in the cytoplasm of the acinar cells. These histopathological changes are fully characteristic of this form of acute pancreatitis. ${ }^{-1113}$ By contrast and consistent with the macroscopic observations and pancreas weight data (Table), the histological appearance of the pancreas of rats given high dose allopurinol+caerulein was uniformly characterised by a marked reduction in the extent of interstitial oedema and a diminution in the numbers and size of acinar cell vacuoles. A detailed quantitative, morphometric analysis of these changes, however, was not undertaken in the present study.

\section{Discussion}

The results of the present study indicate that a high dose $(20 \mathrm{mg} / \mathrm{kg} / \mathrm{h})$ iv infusion of allopurinol for six hours significantly prevents pancreas oedema, weight gain, and rises in serum amylase concentrations in conscious rats with caerulein induced acute pancreatitis. By contrast, an iv infusion with low dose (10 $\mathrm{mg} / \mathrm{kg} / \mathrm{h}$ ) allopurinol for six hours failed to attenuate caerulein-induced acute pancreatitis. These observations coupled with reported beneficial effects of allopurinol in different animal models of acute pancreatitis $^{+5}$ support the concept that allopurinol, through its inhibition of xanthine oxidase, provides protection against acute pancreatitis by blocking the generation of superoxide anion. The failure of low dose allopurinol to provide any protection against acute pancreatitis induction by caerulein may be related to its inability to effectively inhibit the activity of xanthine oxidase at the concentrations delivered. Saluja $e t$ a $l^{15}$ have also recently reported in abstract form that treatment of rats with allopurinol reduced caerulein induced pancreatic oedema, but failed to alter serum amylase concentrations whereas the present study showed that allopurinol significantly reduced both parameters. The study by Saluja and coworkers, ${ }^{15}$ however, used a lower dose of allopurinol for a shorter duration than that used in the present study.

In preliminary studies (data not shown) we established that continuous iv infusions of allopurinol at concentrations of $40-50 \mathrm{mg} / \mathrm{kg} / \mathrm{h}$ were associated with toxic side effects - for example, crystalline deposits in the renal calyces and ureters and significant mortality. By contrast, the effective dose of allopurinol in the present study $(20 \mathrm{mg} / \mathrm{kg} / \mathrm{h})$ for six hours did not produce any early or late untoward side effects.

The present study did not address whether allopurinol is capable of ameliorating pre-existing caerulein induced acute pancreatitis in rats. Recent studies by Sarr $e a^{16}$ in an isolated, perfused canine pancreas model of acute pancreatitis have shown, however, that allopurinol given after acute pancreatitis induction is ineffective in arresting the progression of the disease. These latter findings are consistent with the concept that oxygen derived free radical damage to the pancreas in acute pancreatitis is a very early event in the pathogenetic process. ${ }^{116}$ These latter studies were, however, of short duration - for example, four hours, and thus do not rule out possible longer term benefits of allopurinol inhibition of pancreatic xanthine oxidase in acute pancreatitis.

The mechanisms by which oxygen derived free radicals participate in the pathogenesis of caerulein induced acute pancreatitis is unclear although these compounds are known to damage cell membrane lipids, proteins, and DNA. ${ }^{17-211}$ Oxygen derived free radicals produced locally within the pancreas may also contribute to tissue damage via generation of chemotactic factors for neutrophils which in turn augment the inlammatory process. ${ }^{21}$ While neutrophil depletion studies have suggested a lack of a direct role for leucocytes in the pathogenesis of acute pancreatitis in isolated, perfused canine pancreas models,,$^{22}$ we are unaware of any studies which have been conducted on neutrophil involvement in acute pancreatitis in conscious, intact animals.

The demonstration in this and other studies ${ }^{451}$ 
that allopurinol is beneficial in reducing the severity of acute pancreatitis in diverse animal models of the disease and that oxygen free radical scavenging enzymes - for example, superoxide dismutase and catalase, administered to rats with caerulein induced acute pancreatitis partially attenuates the pancreatitic process, ${ }^{2.3}$ underscores the concept that generation of oxygen derived free radicals via xanthine oxidase represents an apparent early and perhaps pivotal mechanism in the pathogenesis of acute pancreatitis.

The authors thank Mrs Ruth McLaughlin for expert technical assistance. This work was supported in part by an NIH grant DHSS 1 RO1 AM3422-03 to IGR and JRW.

\section{References}

1 Sanfey H, Sarr MG, Bulkley GB, Cameron JL. Oxygenderived free radicals and acute pancreatitis: a review. Acta Physiol Scand 1986; 548: suppl 109-18.

2 Sanfey H, Bulkley GB, Cameron JL. Pathogenesis of acute pancreatitis: role of oxygen free radicals. Surg Forum 1983; 34: 222-4.

3 Sanfey H, Bulkley GB, Cameron JL. The role of oxygen-derived free radicals in the pathogenesis of acute pancreatitis. Ann Surg 1984; 200: 405-13.

4 Sanfey H, Bulkley GB, Cameron JL. The source and role of oxygen-derived free radicals in three different experimental models. Ann Surg 1985; 201: 633-9.

5 Rutledge PL, Saluja AK, Powers RE, Steer ML. Role of oxygen-derived free radicals in diet-induced hemorrhagic pancreatitis in mice. Gastroenterology 1987; 93: 41-7.

6 Lampel M, Kern HF. Acute interstitial pancreatitis in the rat induced by excessive doses of a pancreatic secretagogue. Virchows Arch A Pathol Histol 1977; 373: 97-117.

7 Adler G, Rohr G, Kern HF. Alteration of membrane fusion as a cause of acute pancreatitis in rats. Dig Dis Sci 1982; 27: 983-1002.

8 Renner IG, Wisner JR Jr, Rinderknecht H. Protective effects of exogenous secretin on ceruletide-induced acute pancreatitis in rats. J Clin Invest 1983; 72: 1081-92.

9 Watanabe O, Baccino FM, Steer ML, Meldolesi J. Effects of supramaximal caerulein stimulation on the ultrastructure of the rat pancreatic acinar cell: early morphological changes during development of acute pancreatitis. Am J Physiol 1984; 246: G457-67.

10 Steer ML, Meldolesi J, Figarella C. Pancreatitis: the role of lysosomes. Dig Dis Sci 1984; 29: 934-8.

11 Niederau C, Ferrell LD, Grendell JH. Caeruleininduced acute necrotizing pancreatitis in mice: protective effects of proglumide, benzotript, and secretin. Gastroenterology 1985; 88: 1192-204.

12 Renner IG, Wisner JR Jr, Lavigne BC. Partial restoration of pancreatic function by exogenous secretin in rats with ceruletide-induced acute pancreatitis. Dig Dis Sci 1986; 31: 305-13.

13 Wisner JR Jr, Renner IG, Grendell JH, Niederau C, Ferrell LD. Gabexate mesilate (FOY) protects against ceruletide-induced acute pancreatitis in the rat. Pancreas 1987; 2: 181-6.

14 Adler HL, Roessler EB. Introduction to probability and statistics. San Francisco: WH Freeman and Co, 1968.

15 Saluja A, Powers RE, Saluja M, Rutledge PL, Steer ML. The role of oxygen-derived free radicals in caerulein-induced pancreatitis [Abstract]. Gastroenterology 1986; 90: 1613.

16 Sarr MG, Bulkley GB, Cameron JL. Temporal efficacy of allopurinol during the induction of pancreatitis in the ex vivo perfused canine pancreas. Surgery 1987; 101: 342-6.

17 McCord JM, Roy RS. The pathophysiology of superoxide: roles in inflammation and ischemia. Can $J$ Biochem Physiol Pharmacol 1982; 60: 1346-52.

18 Parks DA, Bulkley GB, Granger DN. Role of oxygenderived free radicals in digestive tract diseases. Surgery 1983; 94: 415-22.

19 Slater TF. Free-radical mechanisms in tissue injury. Biochem J 1984; 222: 1-15.

20) Proctor PH, Reynolds ES. Free radicals and disease in man. Physiol Chem Physics Medical NMR 1984; 16: 175-95.

21 Fantone JC, Ward PA. Oxygen-derived free radicals and their metabolites: relationship to tissue injury. Current concepts. Kalamazoo, Mich: The Upjohn Co, 1985.

22 Sarr MG, Bulkley GB, Cameron JL. The role of leucocytes in the production of oxygen-derived free radicals in acute experimental pancreatitis. Surgery 1987; 101: 292-6.

23 Guice KS, Miller DE, Oldham KT, Townsend CM, Thompson JC. Superoxide dismutase and catalase: a possible role in established pancreatitis. Am J Surg 1986; 151: $163-9$. 